\title{
Efficacy of Combination Colonoscopy Using Modified Cap-assisted and Water-exchange Colonoscopy with Prone Position in the Detection of Colorectal Adenomas: A Retrospective Study
}

Jihwan Ko

Baekyang Jeil Internal Medicine Clinic

Hyung Wook Kim ( $\sim$ mdkhwook@gmail.com )

Pusan National University School of Medicine and Research Institute for Convergence of Biomedical Science and Technology, Pusan National University Yangsan Hospital

Byung Gu Ko

Baekyang Jeil Internal Medicine Clinic

Seong Ho Han

Baekyang Jeil Internal Medicine Clinic

\section{Research Article}

Keywords: Cap-assisted colonoscopy, Water-exchange colonoscopy, Prone position, Adenoma, Polyp

Posted Date: June 2nd, 2021

DOI: https://doi.org/10.21203/rs.3.rs-541472/v1

License: (c) (1) This work is licensed under a Creative Commons Attribution 4.0 International License.

Read Full License 


\section{Abstract}

Background: The efficacy of cap-assisted and water-exchange colonoscopy for adenoma detection, individually or in combination, is well documented but the efficacy of the combination colonoscopy using the above methods with prone position for adenoma detection is unclear. We compared the effectiveness of the combination colonoscopy using modified cap-assisted and water-exchange colonoscopy with prone position (CWP) and conventional colonoscopy (CC) for adenoma detection.

Methods: A total of 746 patients who underwent either CWP or CC, performed by two board-certified gastroenterologists between December 2019 and March 2020, were investigated retrospectively. Capassisted colonoscopy was modified using hooking and dragging maneuver. We evaluated the polyp detection rate (PDR), adenoma detection rate (ADR), and mean number of adenomas detected per procedure (MAP).

Results: There was no significant difference in sex, age, the indication of colonoscopy and quality of bowel preparation between the two groups. The PDR, ADR, and proximal MAP were significantly higher in the CWP group than the CC group (PDR: $84.9 \%$ vs. 59.8\%, $P<0.001$; ADR: $70.1 \%$, vs. $49.2 \%, P<0.001$; proximal MAP: 1.24 vs. $0.55, P<0.001)$. Amongst males, total and proximal MAP were significantly higher in the CWP group than the CC group, respectively $(2.28 \pm 2.24 v s .1 .49 \pm 1.92, P<0.001 ; 1.73 \pm$ 1.98 vs. $0.74 \pm 1.21, P<0.001)$.

Conclusions: Combination colonoscopy is more effective than conventional colonoscopy for the PDR, $A D R$, and proximal MAP. Further studies assessing the synergistic or complementary effects of the combination are needed.

\section{Background}

Colorectal cancer is the third leading cause of new cancer cases and the second leading cause of cancer deaths worldwide [1]. Screening for colorectal cancer using colonoscopy has several advantages, including highly sensitive detection and a single-step diagnosis and treatment of cancer and precancerous lesions [2]. In addition, several studies have reported the efficacy of screening colonoscopy in preventing the incidence of and deaths from colorectal cancer [3-6]. However, despite the many advantages of screening colonoscopy, it has a drawback - detecting cancer and precancerous lesions using colonoscopy is operator dependent $[7,8]$.

Among many quality indicators for monitoring operator dependency, the adenoma detection rate (ADR) and the mean number of adenomas detected per procedure (MAP) are the most sensitive indicators of the quality of colonoscopy [9-11]. Many studies have focused on the improvement of these quality indicators, and new techniques have been developed, such as cap-assisted colonoscopy [12], waterexchange colonoscopy [13], and a combination of the above two methods [10]. Cap-assisted colonoscopy, with a transparent hood fitted to the tip of the colonoscope, allows better mucosal exposure, particularly in the regions behind the proximal aspect of the haustral folds; it also decreases the cecal 
intubation time. Water-exchange colonoscopy provides the advantage of additional cleansing and may aid in optimizing the mucosal examination [14].

Combining the aforementioned methods can assist endoscopists in each phase of the colonoscopyinsertion, inspection, and intervention [10]. Thus, devising a method that can increase ADR and MAP without using complicated devices, such as Endocuff, Endocuff-Vision, or Endorings [15], which cannot be applied in clinical settings because of the restrictions of the National Health Insurance system, and determining whether there is any synergistic effect with the simultaneous use of several methods are of vital importance. The addition of prone positioning to the combination of cap-assisted and waterexchange colonoscopy may prevent loop formation by redistributing abdominal pressure [16]. Therefore, we aimed to compare the ADR between the conventional colonoscopy (CC) and combination colonoscopy (CWP, a combination of modified cap-assisted and water-exchange colonoscopy with the patient in the prone position).

\section{Methods}

\section{Study Design}

This single-center, retrospective, case-control study was conducted at Baekyang Jeil Internal Medicine Clinic, Busan, South Korea. All procedures performed in studies involving human participants were performed in accordance with the ethical standards of the institutional and/or national research committee and with the 1964 Helsinki Declaration and its later amendments or comparable ethical standards. This study was approved by the ethics committee of the Institutional Review Board (IRB) of Pusan National University, Yangsan Hospital (IRB number: 05-2020-126). Informed consent was obtained from all participants included in the study.

\section{Patients}

Between December 2019 and March 2020, a total of 901 patients underwent colonoscopies at our clinic. Informed consent was obtained from all participants included in the study. In total, 442 patients underwent CWP and 459 underwent CC. The procedures were performed by two board-certified gastroenterologists, J.K. and S.H.H. S.H.H. had 10 years of experience in conventional colonoscopy, and J.K. had 3 years of experience in conventional colonoscopy and 1 year in combination colonoscopy. The exclusion criteria were age $<18$ years, failed cecal intubation, and poor or inadequate bowel preparation. Finally, among the 746 enrolled patients, 358 and 388 patients were included in the CWP and CC group, respectively. The study groups were not randomized. Each patient chose a doctor to perform their colonoscopy. Based on the indication for colonoscopy, the patients were divided into the following two groups: 1) had a positive fecal occult blood test (FOBT) and, were financially supported by the National Health Insurance System; 2) either had a negative FOBT or did not undergo FOBT, and were using their finances for the investigations related to polyps or cancer. In South Korea, the National Health Insurance System encourages people aged over 50 years to undergo an FOBT annually; if the test result is positive, 
it provides financial support for the colonoscopy. Since the proportion of patients with positive FOBT could affect the ADR [17], for each group, we compared the number of patients with positive FOBT.

\section{Endoscopic Procedure}

In this study, two board-certified gastroenterologists performed colonoscopies-one had performed more than 10,000 CC procedures, and the other had performed more than 3,000 CWP procedures before the study period. No association had been reported between the procedural volume and the ADR; therefore, we assumed that the difference in the procedural volume between the two doctors would not affect the ADR [18].

Colonoscopies were performed after preparing the bowel with $2 \mathrm{~L}$ of polyethylene glycol plus an ascorbic acid solution (Coolprep, Taejun, Seoul, Korea; Readyfree, Intropharm Tech., Gyeonggi-do, Korea). Bowel preparation was evaluated and graded using the Aronchick scale [19]. Colonoscopies were performed with EPK-i5000 (Pentax EPKi processor) and EC38-i10F colonoscopes (Pentax, Tokyo, Japan). A transparent cap was attached to the tip of the colonoscope (Finemedix Co. Ltd, Daegu, Korea). The modified cap-assisted colonoscopy, referred to as the "hooking and dragging method," was performed by simultaneous hooking (gentle bending of the tip of the colonoscope towards the wall of the colon) and dragging (gentle retraction of the colonoscope dragging it down the multiple folds of the colon) the colonoscope down the colonic folds; for the procedure, a transparent hood was fitted onto the tip of the colonoscope [20].

The colonoscopies were performed with the patients under midazolam-based conscious sedation. When polyps were detected, endoscopic analysis and therapeutic interventions were carried out during the withdrawal phase. For both the procedures, the patients were initially made to lie in the left decubitus position. When the colonoscope reached the sigmoid colon, the patients in the CWP group repositioned themselves to a prone position and maintained the posture until the end of the procedure. During the colonoscopy, the patients used a hugging pillow to avoid chest compression; their saturation levels were monitored. The patients were sedated minimally as their cooperation was needed during the procedure for changing the position.

In the CWP group, the colonoscope with the waterjet system was inserted into the rectum with the air pump turned off. Residual air and fluid were immediately suctioned out of the colon, and warm water (at $37^{\circ} \mathrm{C}$ ) was infused. The scope was advanced, and in each colonic segment, this exchange (removal of residual air and stool and infusion of sterile water) was performed. The appendiceal orifice was identified; then the water was suctioned and the air was insufflated to facilitate the inspection and removal of the lesions. Upon the withdrawal of the scope, a transparent cap was used, and the haustral folds were flattened, to facilitate mucosal inspection. The air was insufflated to distend the lumen of the colon during scope insertion in the CC group. The water was used for irrigation only if bubbles or residual debris were encountered.

\section{Polyps}


Polyps with a diameter of $\geq 5 \mathrm{~mm}$ were removed by endoscopic mucosal resection or cold snare polypectomy. Polyps with a diameter of $<5 \mathrm{~mm}$ were removed with cold forceps polypectomy. All the removed polyps were examined pathologically, and the number of adenomas was determined. In this study, we defined the polyp detection rate (PDR) as the proportion of patients with at least one polyp, ADR as the proportion of patients with at least one adenoma, and MAP as the mean number of adenomas detected per procedure (total number of adenomas/total number of procedures).

\section{Outcome Measures and Statistical Analysis}

The primary outcome was the comparison of the ADR between CWP and CC groups. The secondary outcome was the comparison of the PDR and the MAP between these two groups. In addition, MAP in the proximal colon (proximal MAP) and the distal colon (distal MAP) were evaluated. The proximal colon was defined as the colon proximal to the splenic flexure, including the cecum, ascending colon, and transverse colon.

Statistical comparisons between the two groups were performed using the Student t-test, and the ADR and PDR were analyzed using Fisher's exact test. A $P$ value of $<0.05$ indicated statistical significance. The statistical analyses were performed using SPSS 26 (IBM Corp., Armonk, NY, USA).

\section{Results}

\section{Patient Characteristics}

The baseline characteristics between CWP and CC groups are summarized in Table 1. A total of 746 colonoscopies, including $358 \mathrm{CWP}$ and $388 \mathrm{CC}$, were evaluated. The study population was composed predominantly of women (55.4\%); the mean age was 62.9 years. For the indication of colonoscopy, 102 patients (11.3\%) had positive FOBTs. The mean withdrawal time was 829.8 seconds and the ratio of excellent bowel preparation was $76.8 \%$. In the comparison between the two groups, there was no significant difference in sex, age, the indication of colonoscopy and quality of the bowel preparation except for the withdrawal time. Even though not intended, the withdrawal time was significantly longer in the CWP group than in the CC group. $(950.70 \pm 438.45$ vs $718.15 \pm 325.96, P<0.001)$. 
Table 1

Baseline characteristics of the combination and conventional colonoscopy groups

\begin{tabular}{|c|c|c|c|c|}
\hline & $\begin{array}{l}\text { Total }(n \\
=746)\end{array}$ & $\begin{array}{l}\text { Combination } \\
\text { colonoscopy }(n=358)\end{array}$ & $\begin{array}{l}\text { Conventional } \\
\text { colonoscopy }(n=388)\end{array}$ & $P$-value \\
\hline Sex, n (\%) & 333 & $165(46.1)$ & $168(43.3)$ & 0.462 \\
\hline Male & $(44.0)$ & $193(53.9)$ & $220(56.7)$ & \\
\hline Female & $(55.4)$ & & & \\
\hline Age, years* & $\begin{array}{l}62.9 \pm \\
7.8\end{array}$ & $62.4 \pm 7.7$ & $63.3 \pm 7.9$ & 0.085 \\
\hline Positive FOBT, n (\%) & $\begin{array}{l}102 \\
(11.3)\end{array}$ & $51(11.5 \%)$ & $51(11.1)$ & 0.916 \\
\hline Withdrawal time, sec* & $\begin{array}{l}829.8 \pm \\
401.0\end{array}$ & $950.7 \pm 438.5$ & $718.1 \pm 326.0$ & $<0.001$ \\
\hline $\begin{array}{l}\text { Bowel preparation } \\
\text { (Aronchick scale), n (\%) }\end{array}$ & & & & 0.092 \\
\hline Fair & $42(5.6)$ & $14(3.9)$ & $28(7.2)$ & \\
\hline Good & $\begin{array}{l}131 \\
(17.6)\end{array}$ & $59(16.5)$ & $72(18.6)$ & \\
\hline Excellent & $\begin{array}{l}573 \\
(76.8)\end{array}$ & $285(79.6)$ & $288(74.2)$ & \\
\hline
\end{tabular}

FOBT, Fecal occult blood test

*Age and withdrawal time are represented as mean \pm standard deviation (range)

\section{Polyp and Adenoma Detection Rate}

The comparison of PDR and ADR between CWP and CC groups is summarized in Table 2. A total of 536 patients had $\geq 1$ polyp, with 304 patients (PDR: $84.9 \%$ ) in the CWP group and 232 patients (PDR: $59.8 \%$ ) in the CC group. The PDR was significantly high among the patients, of both sexes, in the CWP group ( $P<$ 0.001). A total of 442 patients (59.2\%) had $\geq 1$ adenoma, with 251 patients (ADR: 70.1\%) in the CWP group and 191 patients (ADR: $49.2 \%$ ) in the CC group. The ADR was significantly high among the patients, of both sexes, in the CWP group $(P<0.001)$. The MAP was also significantly higher in the CWP group than in the CC group $(1.69 \pm 1.93 v s .1 .06 \pm 1.59, P<0.001)$. The proximal MAP was significant higher in the CWP group than in the CC group (1.24 \pm 1.63 vs. $0.55 \pm 1.01, P<0.001)$; however, the distal MAP was not different between the two groups $(0.46 \pm 0.78 v s .0 .51 \pm 1.02, P=0.405)$.

The comparison of MAP by sex between CWP and CC groups is summarized in Table 3. Amongst males, total and proximal MAP in the CWP group were significantly higher than in the CC group, respectively. ( $2.28 \pm 2.24$ vs. $1.49 \pm 1.92, P<0.001 ; 1.73 \pm 1.98$ vs. $0.74 \pm 1.21, P<0.001)$. Amongst females, total and proximal MAP in the CWP group were significantly higher than in the CC group, respectively. $(1.19 \pm 1.45$ 
vs. $0.73 \pm 1.18, P<0.001 ; 0.83 \pm 1.11$ vs. $0.40 \pm 0.78, P<0.001$ ) In contrast, for both sexes, the distal MAP was not different between two groups.

Table 2

Comparison of polyp and adenoma detection rate between the combination and conventional colonoscopy groups

\begin{tabular}{|c|c|c|c|}
\hline & $\begin{array}{l}\text { Combination colonoscopy ( } \mathrm{n} \\
=358 \text { ) }\end{array}$ & $\begin{array}{l}\text { Conventional colonoscopy ( } \mathrm{n} \\
=388 \text { ) }\end{array}$ & $P$-value \\
\hline \multicolumn{4}{|c|}{$\begin{array}{l}\text { Polyp detection rate, } \mathrm{n} \\
(\%)\end{array}$} \\
\hline Total & 304 (84.9) & $232(59.8)$ & $<0.001$ \\
\hline Female & 152 (78.7) & 117 (53.2) & $<0.001$ \\
\hline Male & 152 (92.1) & 115 (68.4) & $<0.001$ \\
\hline \multicolumn{4}{|c|}{$\begin{array}{l}\text { Adenoma detection rate, } \\
\mathrm{n}(\%)\end{array}$} \\
\hline Total & $251(70.1)$ & $191(49.2)$ & $<0.001$ \\
\hline Female & $116(60.1)$ & $89(40.4)$ & $<0.001$ \\
\hline Male & 135 (82.8) & 102 (60.7) & $<0.001$ \\
\hline \multicolumn{4}{|l|}{ MAP, $n^{\star}$} \\
\hline Total & $1.69 \pm 1.93$ & $1.06 \pm 1.59$ & $<0.001$ \\
\hline Proximal & $1.24 \pm 1.63$ & $0.55 \pm 1.01$ & $<0.001$ \\
\hline Distal & $0.46 \pm 0.78$ & $0.51 \pm 1.02$ & 0.405 \\
\hline \multicolumn{4}{|c|}{ MAP, mean number of adenomas detected per procedure } \\
\hline *MAP is $r$ & In \pm standard deviation (range) & & \\
\hline
\end{tabular}


Table 3

Comparison of the mean number of adenomas detected per procedure (MAP) by sex between the combination and conventional colonoscopy groups

\begin{tabular}{|llll|}
\hline MAP, $\mathrm{n}^{*}$ & Combination colonoscopy & Conventional colonoscopy & $P$-value \\
\hline Male & & & \\
\hline Total & $2.28 \pm 2.24$ & $1.49 \pm 1.92$ & $<0.001$ \\
\hline Proximal & $1.73 \pm 1.98$ & $0.74 \pm 1.21$ & $<0.001$ \\
\hline Distal & $0.57 \pm 0.86$ & $0.74 \pm 1.23$ & 0.136 \\
\hline Female & & & $<0.001$ \\
\hline Total & $1.19 \pm 1.45$ & $0.73 \pm 1.18$ & $<0.001$ \\
\hline Proximal & $0.83 \pm 1.11$ & $0.40 \pm 0.78$ & 0.723 \\
\hline Distal & $0.36 \pm 0.68$ & $0.33 \pm 0.78$ & \\
\hline *MAP is represented as mean \pm standard deviation (range) & \\
\hline
\end{tabular}

\section{Discussion}

Screening colonoscopy is used widely in the prevention of colorectal cancer. Among the quality indicators governing the efficacy of colonoscopy, the ADR and MAP are important indicators that may lead to a decrease in the rate of interval cancer $[9,11]$. Although several methods, such as Endocuff, EndocuffVision, or Endorings, have been studied for these two quality indicators [15]; in countries with a National Health Insurance System, there are limitations in adopting these methods for private clinics. Therefore, it is important to determine whether the ADR can be increased using conventional methods.

In this study, the combination colonoscopy, including modified cap-assisted and water-exchange colonoscopy with prone position, was effective in the detection of polyps and adenomas, especially those in the proximal colon. These results may have been associated with the synergistic or complementary effects during the insertion and withdrawal phases.

During the insertion (water exchange) phase, the transparent hood prevents the occlusion of the suction channel by creating a space between the mucosa and the suction port; besides, the continuous water exchange prevents the settlement of debris onto the cap attachment. This interaction enables uninterrupted water exchange and a clear visualization during the insertion phase. Also, combination colonoscopy induces a synergistic effect, resulting in the prevention of loop formation and facilitation of cecal intubation by the following mechanisms: 1) the cap-assisted colonoscopy provides better visualization of the lumen in the colonic flexures and the sigmoid colon, facilitating the advancement of the endoscope without forming excessive loops and inadequate air insufflation [21], 2) the waterexchange colonoscopy minimizes the colonic distension, facilitating the advancement of the endoscope without forming excessive loops, 3) prone positioning, owing to the patient's body weight, provides 
generalized abdominal pressure; it may allow the passage of the colonoscope in specific instances, such as when large loops, that are otherwise challenging to resolve, form in the transverse colon [16, 22]. While these effects may not facilitate the effective inspection of the mucosa directly, they enable the effective movement of the colonoscopic tip and allows the endoscopist to concentrate, without exhaustion, particularly while inspecting the mucosa during the withdrawal phase.

On water-exchange colonoscopy, mucosal inspection was effortless during the withdrawal phase because of the improved quality of cleanliness [13], while on cap-assisted colonoscopy, the proximal aspect of the colon, especially the proximal side of mucosal folds on the proximal colon and the inner curvatures of the colonic flexures, could be better visualized because of the flattening of the haustral folds [23-25]. This may explain why the proximal MAP, but not the distal MAP, showed a significant increase in the CWP group. We also used a modified version of the cap-assisted colonoscopy, referred to as the "hooking and dragging maneuver" [20]. The conventional cap-assisted colonoscopy flattened a single mucosal fold [26], while the modified cap-assisted colonoscopy hooked (gentle bending of the tip of the colonoscope towards the wall of the colon) and dragged (gentle retraction of the colonoscope, dragging the multiple folds of the colon) multiple mucosal folds simultaneously [20]. This modified method simultaneously allowed the inspection of the proximal and distal parts of the mucosal folds, minimizing blind spots. Figures 1, 2 and 3 shows the use of the hooking and dragging maneuver in locating hidden polyps in multiple cases, correlated with real-world cases.

The ' $a-1$ ' and 'b-1' shows the view without the 'hooking and dragging maneuver'. In this view, the polyp, which is at the proximal side of the mucosal fold, is hidden. However, when $\nabla$ hooking (gentle bending of the tip of the colonoscope towards the wall of the colon) and $₫$ dragging (gentle retraction of the colonoscope dragging the multiple folds of the colon) is performed (a-2), the hidden polyp at the proximal side of the mucosal fold becomes visible (b-2). The arrowhead (b-1) indicates the position where the polyp was hidden.

The ' $a-1$ ' and ' $b-1$ ' shows the view without the 'hooking and dragging maneuver'. In this view, LST, which is between mucosal folds, is hidden. However, when hooking and dragging is performed (a-2), the hidden LST between the mucosal folds becomes visible (b-2). The arrowhead (b-1) indicates the position where LST was hidden. The submucosal injection is being administered (b-3), and the endoscopic mucosal resection (EMR) is being performed $(b-4)$.

The ' $a-1$ ' and 'b-1' shows the view without the 'hooking and dragging maneuver'. In this view, the LST, overlying multiple mucosal folds, is hidden. However, when hooking (a-2) and dragging (a-3) is performed, the hidden LST overlying the multiple mucosal fold becomes visible (b-2). The arrowhead indicates the position where LST was hidden (b-1).

The submucosal injection is being administered (b-3), and the endoscopic mucosal resection (EMR) is being performed (b-4). 
In this study, the ADR in the CWP group (70.1\%) as well as in the CC group (49.2\%) were higher than that of previous studies with $40.5 \%$ in cap-assisted colonoscopies (meta-analysis) [27], 41.7\% in water exchange colonoscopies (network meta-analysis) [13], and 44\% in cap-assisted water immersions (singlecenter trial) [28]. The high ADR in both groups could be associated with the high quality colonoscopy with long withdrawal time. The significantly longer withdrawal time in the CWP group compared to the CC group was not only due to the additional time required for subsequent polypectomies that resulted from high detection rates but also because of the "hooking and dragging maneuver" in the modified capassisted colonoscopy.

In the MAP, the total and proximal MAP in the CWP group was significantly higher than that in the CC group $(1.69 \pm 1.93$ vs $1.06 \pm 1.59, P<0.001 ; 1.24 \pm 1.63$ vs $0.55 \pm 1.01, P<0.001)$. This effect may be related to the characteristics of the proximal colon-a greater height of the haustral fold and more residual debris than the distal colon. In the proximal colon, the use of cap-assisted colonoscopies and water-exchange colonoscopies can facilitate withdrawal inspection by flattening the semilunar folds and improving the quality of cleanliness, respectively.

According to the study by Yen et al. [10], investigating the combination colonoscopy without the prone position, the ADR for the combination of the water-exchange and cap-assisted colonoscopies was $75 \%$ (PDR, 93.0\%; proximal colon ADR, 61\%; adenoma per colonoscopy, 2.70) and was consistent with the ADR of this study. However, the MAP $(1.69 \pm 1.93)$ of this study was lower than the MAP $(2.70 \pm 3.27)$ obtained in their study [10]. Considering that most of the participants in the study by Yen et al. were males (male, 95; female, 5), we evaluated PDR, ADR, MAP and proximal MAP according to sex. In this study, the PDR, ADR, and MAP in males were $92.1 \%, 82.8 \%$, and $2.28 \pm 2.24$, respectively. The high ADR in both studies demonstrated that the combination of cap-assisted and water-exchange colonoscopies facilitated the detection of adenomas by the aforementioned synergistic or complementary effects. Yen et al. used Olympus PCF-H180AL colonoscope (Olympus Medical Systems Corp. Shinjuku City, Tokyo, Japan), with variable stiffness capability, in patients without changing their posture to the prone position, however, the prone position can be helpful while using a colonoscope without variable stiffness capability.

This study had some limitations. First, this was a retrospective study and was performed in a single center; hence, the potential selection or information bias may have existed. Second, we could not investigate the patients' family history of colorectal cancer and insertion time, which could have influenced ADR [29,30], and body mass index, which could have led to an increase in loop formation [31]. Third, the endoscopists were non-blinded to the methods used in this study, which may have been a potential source of investigator bias. Fourth, only two of the endoscopists participated in this study, and they performed only one method according to their skill proficiency.

\section{Conclusions}


The PDR, ADR, and proximal MAP in the CWP group were significantly higher than that in the CC group, suggesting that combination colonoscopy could be more useful than conventional colonoscopy for adenoma detection. Although this technique can improve the rate of adenoma detection, further evaluation to assess the synergistic or complementary effects is required.

\section{Abbreviations}

CWP: combination colonoscopy using modified cap-assisted and water-exchange colonoscopy with the prone position; CC: conventional colonoscopy; PDR: polyp detection rate; ADR: adenoma detection rate; MAP: mean number of adenomas detected per procedure; FOBT: fecal occult blood test.

\section{Declarations}

\section{Acknowledgments}

Not applicable.

\section{Authors' contributions}

JK drafted the manuscript and formulated the study design and concept. HWK performed critical revision of the manuscript. BGK and SHH performed data collection. All authors read and approved the final manuscript.

\section{Funding}

This study was supported by a 2-Year Research Grant of Pusan National University.

\section{Availability of data and materials}

The datasets used and/or analyzed during the current study are available from the corresponding author on reasonable request.

\section{Ethics approval and consent to participate}

All procedures performed in studies involving human participants were performed in accordance with the ethical standards of the institutional and/or national research committee and with the 1964 Helsinki Declaration and its later amendments or comparable ethical standards. This study was approved by the ethics committee of the Institutional Review Board (IRB) of Pusan National University, Yangsan Hospital (IRB number: 05-2020-126). Informed consent was obtained from all participants included in the study. 


\section{Consent for publication}

Not applicable.

\section{Conflicting interest}

The authors declare that they have no competing interests.

\section{References}

1. Bray F, Ferlay J, Soerjomataram I, Siegel RL, Torre LA, Jemal A. Global cancer statistics 2018 : GLOBOCAN estimates of incidence and mortality worldwide for 36 cancers in 185 countries. CA Cancer J Clin. 2018;68:394-424.

2. Rex DK, Boland CR, Dominitz JA, Giardiello FM, Johnson DA, Kaltenbach T, Levin TR, Lieberman D, Robertson DJ. Colorectal cancer screening: recommendations for physicians and patients from the U.S. Multi-Society Task Force on colorectal cancer. Am J Gastroentero. 2017;112:1016-30.

3. Winawer SJ, Zauber AG, Ho MN, O'Brien MJ, Gottlieb LS, Sternberg SS, Waye JD, Schapiro M, Bond $\mathrm{JH}$, Panish JF et al. Prevention of colorectal cancer by colonoscopic polypectomy. The National Polyp Study Workgroup. N Engl J Med. 1993;329:1977-81.

4. Lieberman D, Moravec M, Holub J, Michaels L, Eisen G. Polyp size and advanced histology in patients undergoing colonoscopy screening: implications for CT colonography. Gastroenterology. 2008;135:1100-5.

5. Nishihara R, Wu K, Lochhead P, Morikawa T, Liao X, Qian ZR, Inamura K, Kim SA, Kuchiba A, Yamauchi $\mathrm{M}$ et al. Long-term colorectal-cancer incidence and mortality after lower endoscopy. $\mathrm{N}$ Engl J Med. 2013;369:1095-105.

6. Brenner H, Chang-Claude J, Jansen L, Knebel P, Stock C, Hoffmeister M. Reduced risk of colorectal cancer up to 10 years after screening, surveillance, or diagnostic colonoscopy. Gastroenterology. 2014;146:709-17.

7. Chen SC, Rex DK. Endoscopist can be more powerful than age and male gender in predicting adenoma detection at colonoscopy. Am J Gastroentero. 2007;102:856-61.

8. Rabeneck L, Paszat LF, Saskin R. Endoscopist specialty is associated with incident colorectal cancer after a negative colonoscopy. Clin Gastroenterol Hepatol. 2010;8:275-9.

9. Kaminski MF, Regula J, Kraszewska E, Polkowski M, Wojciechowska U, Didkowska J, Zwierko M, Rupinski M, Nowacki MP, Butruk E. Quality indicators for colonoscopy and the risk of interval cancer. N Engl J Med. 2010;362:1795-803.

10. Yen AW, Leung JW, Leung FW. A novel method with significant impact on adenoma detection: combined water-exchange and cap-assisted colonoscopy. Gastrointest Endosc. 2013;77:944-8. 
11. Denis B, Sauleau EA, Gendre I, Exbrayat C, Piette C, Dancourt V, Foll Y, Ait Hadad H, Bailly L, Perrin P. The mean number of adenomas per procedure should become the gold standard to measure the neoplasia yield of colonoscopy: a population-based cohort study. Dig Liver Dis. 2014;46:176-81.

12. Nutalapati V, Kanakadandi V, Desai M, Olyaee M, Rastogi A. Cap-assisted colonoscopy: a metaanalysis of high-quality randomized controlled trials. Endosc. Int. Open. 2018;6:E1214-23.

13. Fuccio L, Frazzoni L, Hassan C, La Marca M, Paci V, Smania V, De Bortoli N, Bazzoli F, Repici A, Rex D et al. Water exchange colonoscopy increases adenoma detection rate: a systematic review with network meta-analysis of randomized controlled studies. Gastrointest Endosc. 2018;88:589-97.

14. Yen AW, Leung JW, Leung FW. A new method for screening and surveillance colonoscopy: Combined water-exchange and cap-assisted colonoscopy. J Interv Gastroenterol. 2012;2:114-9.

15. Gkolfakis P, Tziatzios G, Spartalis E, Papanikolaou IS, Triantafyllou K. Colonoscopy attachments for the detection of precancerous lesions during colonoscopy: A review of the literature. World $\mathrm{J}$ Gastroenterol. 2018;24:4243-53.

16. Uddin FS, Iqbal R, Harford WV, Dunbar KB, Cryer BL, Spechler SJ, Feagins LA. Prone positioning of obese patients for colonoscopy results in shortened cecal intubation times: a randomized trial. Dig. Dis. Sci. 2013;58:782-7.

17. Barret M, Boustiere C, Canard JM, Arpurt JP, Bernardini D, Bulois P, Chaussade S, Heresbach D, Joly I, Lapuelle $\mathrm{J}$ et al. Factors associated with adenoma detection rate and diagnosis of polyps and colorectal cancer during colonoscopy in France: results of a prospective, nationwide survey. PloS one. 2013;8:e68947.

18. Forbes N, Boyne DJ, Mazurek MS, Hilsden RJ, Sutherland RL, Pader J, Ruan Y, Shaheen AA, Wong C, Lamidi $\mathrm{M}$ et al. Association Between Endoscopist Annual Procedure Volume and Colonoscopy Quality: Systematic Review and Meta-analysis. Clin Gastroenterol Hepato. 2020;18:2192-208.

19. Pontone S, Angelini R, Standoli M, Patrizi G, Culasso F, Pontone P, Redler A. Low-volume plus ascorbic acid vs high-volume plus simethicone bowel preparation before colonoscopy. World $\mathrm{J}$ Gastroenterol. 2011;17:4689-95.

20. Ko JH. Suggestion of a standard maneuver in cap assisted colonoscopy: Hooking and dragging maneuver. Endoscopy. 2021;Online ahead of print.

21. Matsushita M, Danbara N, Fukui T, Matsumoto T, Uchida K, Omiya M, Okazaki K. Total colonoscopy with a transparent hood for trainees. Am J Gastroenterol. 2007;102:2355-6.

22. Vergis N, Scarborough AJ, Morris JA, Hoare JM. Prone or Left for Colonoscopy? A Randomized Controlled Trial of Prone Versus Left-sided Starting Position for Colonoscopy. J Clin Gastroenterol. 2018;52:e82-6.

23. Lee YT, Hui AJ, Wong VW, Hung LC, Sung JJ. Improved colonoscopy success rate with a distally attached mucosectomy cap. Endoscopy. 2006;38:739-42.

24. East JE, Saunders BP, Burling D, Boone D, Halligan S, Taylor SA. Surface visualization at CT colonography simulated colonoscopy: effect of varying field of view and retrograde view. Am J Gastroenterol. 2007;102:2529-35. 
25. Pickhardt PJ, Nugent PA, Mysliwiec PA, Choi JR, Schindler WR. Location of adenomas missed by optical colonoscopy. Ann Intern Med. 2004;141:352-9.

26. Kim HH, Park SJ, Park MI, Moon W, Kim SE. Transparent-cap-fitted colonoscopy shows higher performance with cecal intubation time in difficult cases. World J. Gastroentero. 2012;18:1953-8.

27. Facciorusso A, Buccino VR, Sacco R. Endocuff-assisted versus Cap-assisted Colonoscopy in Increasing Adenoma Detection Rate: A Meta-analysis. J Gastrointestin Liver Dis. 2020;29:415-20.

28. Falt P, Smajstrla V, Fojtik P, Liberda M, Kliment M, Tvrdik J, Urban O. Cap-assisted water immersion for minimal sedation colonoscopy: prospective, randomized, single-center trial. Dig Endosc. 2013;25:434-9.

29. Henrikson NB, Webber EM, Goddard KA, Scrol A, Piper M, Williams MS, Zallen DT, Calonge N, Ganiats $\mathrm{TG}$, Janssens AC et al. Family history and the natural history of colorectal cancer: systematic review. Genet Med. 2015;17:702-12.

30. Hsieh $\mathrm{YH}, \mathrm{Koo} \mathrm{M}$, Leung FW. A patient-blinded randomized, controlled trial comparing air insufflation, water immersion, and water exchange during minimally sedated colonoscopy. Am J Gastroenterol. 2014;109:1390-400.

31. Anderson JC, Messina CR, Cohn W, Gottfried E, Ingber S, Bernstein G, Coman E, Polito J. Factors predictive of difficult colonoscopy. Gastrointest Endosc. 2001;54:558-62.

\section{Figures}




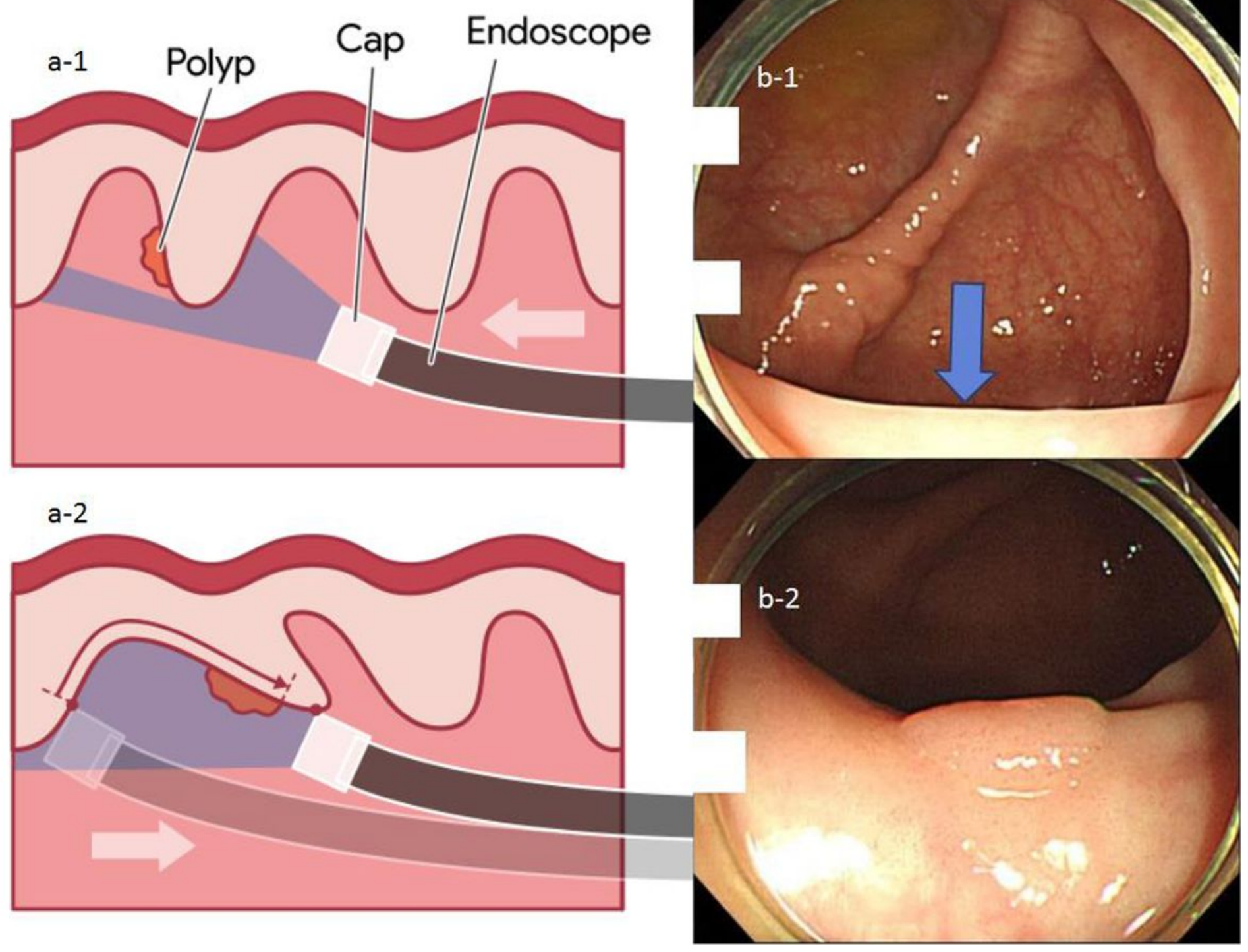

Figure 1

"Hooking and dragging maneuver" revealing hidden polyp 


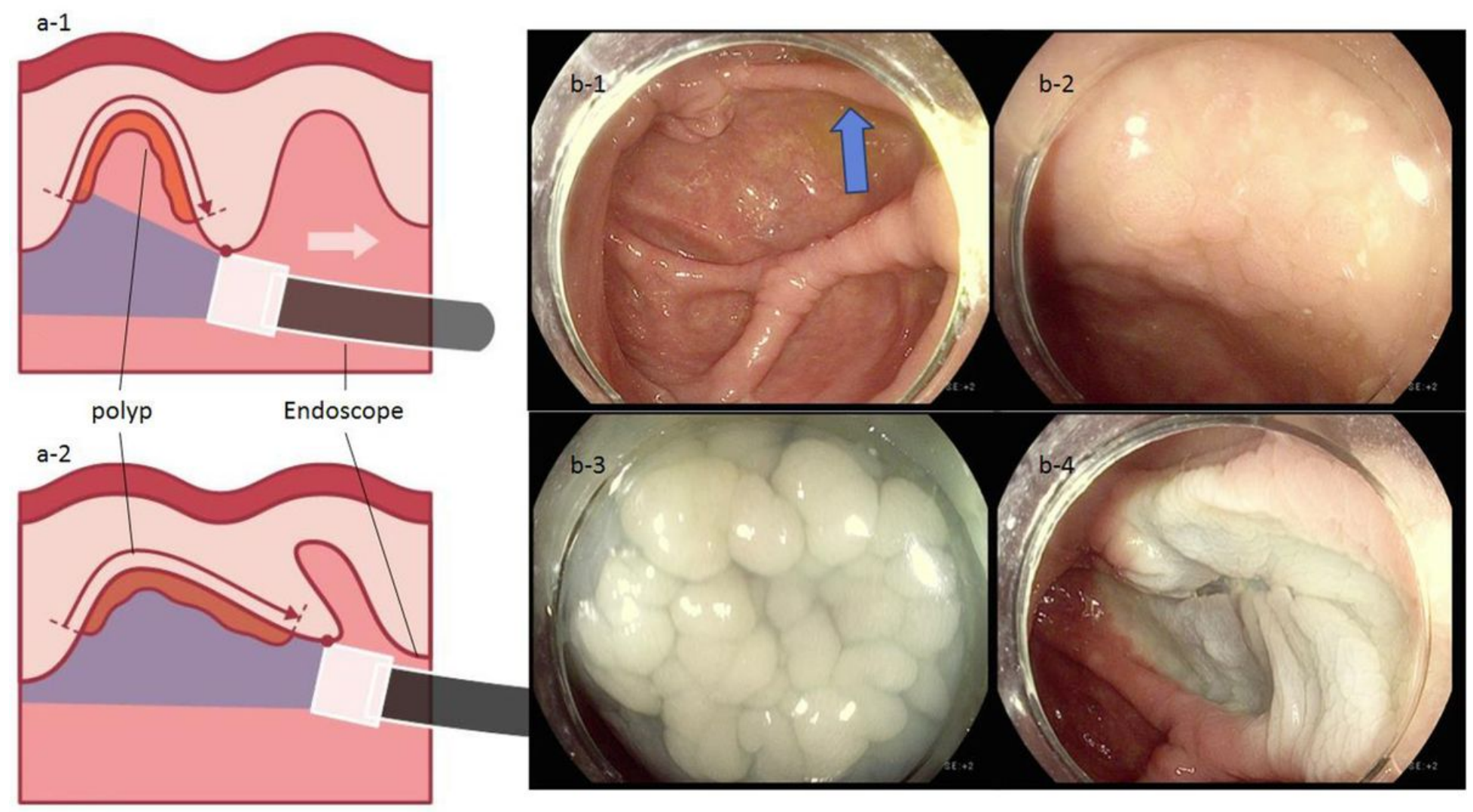

Figure 2

"Hooking and dragging maneuver" revealing the lateral spreading tumor (LST), hidden between mucosal folds 


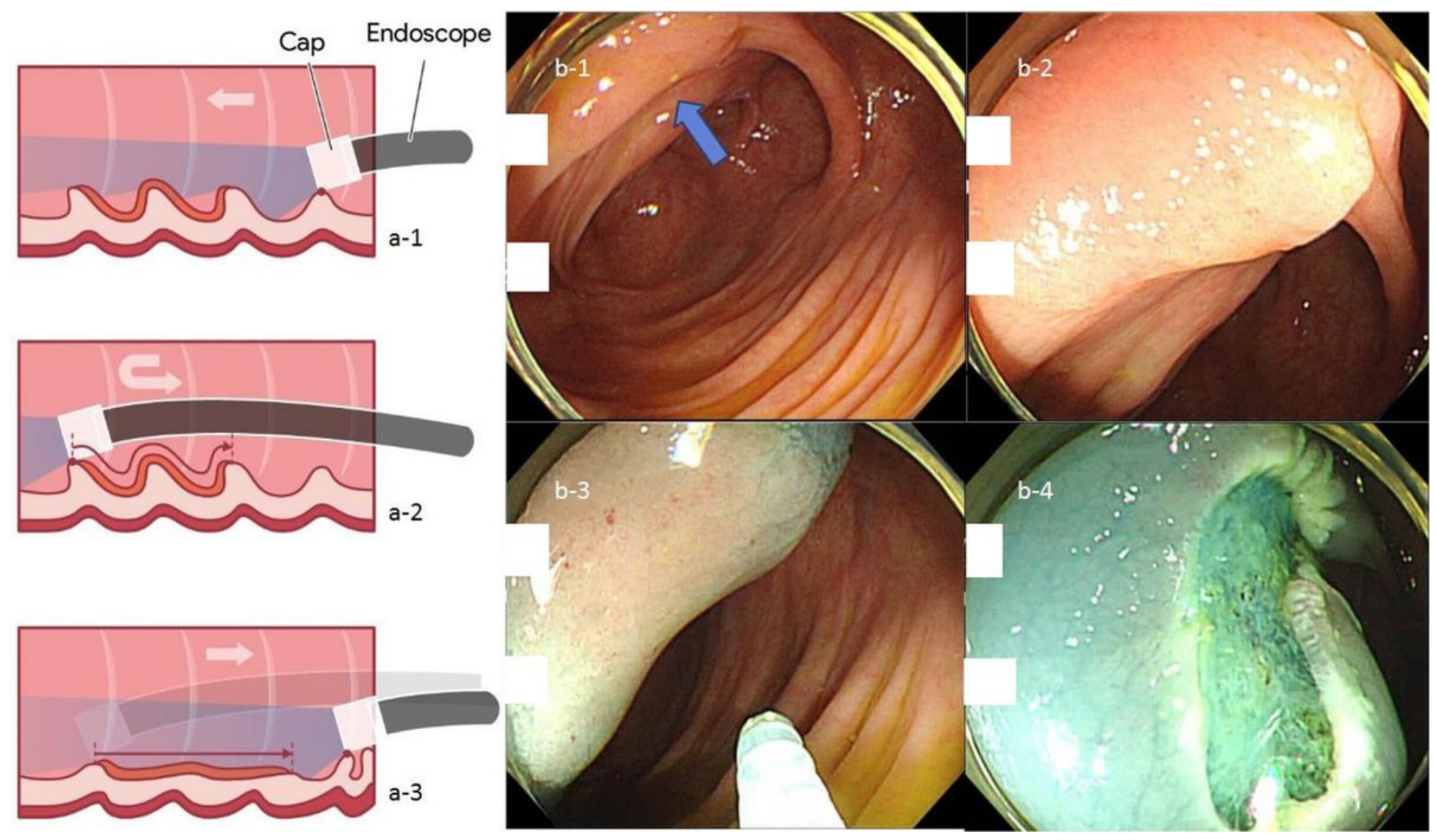

Figure 3

"Hooking and dragging maneuver" revealing hidden lateral spreading tumor (LST), overlying multiple mucosal folds 